health care it requires. To this end, and to best serve its people, it should provide enough medical school positions, and residency training positions in the right number, mix and distribution, as well as access to licensure. This should occur in an equitable manner that ensures diversity that is appropriate to best serving the society in question. Then we will be walking the talk.

\section{REFERENCES}

1 Razack S, Hodges B, Steinert Y, Maguire M. Seeking inclusion in an exclusive process: discourses of medical school student selection. Med Educ 2015;49:36-47.

2 Boelen C, Heck JE, World Health Organization. Defining and Measuring the Social Accountability of Medical Schools. Geneva: WHO 1995. http://apps.who.int/iris/ bitstream/10665/59441/1/
WHO_HRH_95.7. pdf?ua $=1$. [Accessed 15 August 2014.]

3 Association of Faculties of Medicine of Canada. The Future of

Medical Education in Canada - A Collective Vision for $M D$ Education. Ottawa, ON 2010. http://www. afmc.ca/future-of-medicaleducation-in-canada/medicaldoctor-project/pdf/collective_ vision.pdf. [Accessed 15 August 2014].

4 Cleland JA, Nicholson S, Kelly N, Moffat M. Taking context seriously: explaining widening access policy enactments in UK medical schools. Med Educ 2015;49:25-35.

5 Liaison Committee on Medical Education. Functions and Structure of a Medical School: Standards for Accreditation of Medical Education Programs Leading to the MD Degree. Washington, DC 2013. http:// www.lcme.org/publications. htm\#dci. [Accessed 15 August 2014.]
6 Ho M-J, Shaw K, Liu T-H, Norris J, Chiu Y-T. Equal, global, local: discourses in Taiwan's international medical graduate debate. Med Educ 2015;49:48-59.

7 Association of Faculties of Medicine of Canada, College of Family Physicians of Canada, Collège des Médecins du Québec, and Royal College of Physicians and Surgeons of Canada. The Future of Medical Education in Canada - A Collective Vision for Postgraduate Medical Education. Ottawa, ON 2012. http://www. afmc.ca/future-of-medicaleducation-in-canada/ postgraduate-project/pdf/ FMEC_PG_Final-Report_EN.pdf. [Accessed 15 August 2014.]

8 Institute of Medicine. Graduate Medical Education That Meets the Nation's Health Needs. Washington, DC 2014. http://www.iom.edu/ Reports/2014/Graduate-MedicalEducation-That-Meets-the-NationsHealth-Needs.aspx. [Accessed 15 August 2014.]

\title{
Diversity in medical school admission: insights from personnel recruitment and selection
}

Filip Lievens

This issue of Medical Education includes four papers ${ }^{1-4}$ that focus upon recruitment and selection. My personal involvement with this field has occurred through my research on situational judgement tests (SJTs), most of which has been conducted in the broader

Ghent, Belgium

Correspondence: Filip Lievens, Department of Personnel Management and Work and Organisational Psychology, Ghent

University, Henri Dunantlaan 2, 9000

Ghent, Belgium. Tel: 0032926464 53;

E-mail: Filip.Lievens@UGent.be

doi: $10.1111 /$ medu. 12615 field of personnel recruitment and selection for the workforce. ${ }^{5}$ As such, I read the four studies ${ }^{1-4}$ with two questions in mind: (i) on what issues have the respective strands of recruitment and selection diversity research in the medical education and workforce domains converged? (ii) What new insights emerging from workforce diversity can inform medical education research?

My overall view is that strategies for increasing diversity in medical education should be conceptualised in a broader attraction- selection-inclusion-retention (ASIR) framework. ${ }^{6}$ In this commentary, I focus on the first two stages of this ASIR cycle, namely the attraction and selection of students with under-represented minority (URM) backgrounds, although I acknowledge the need for further efforts to include and retain URM students in the medical education pipeline.

Strategies for increasing diversity in medical education should be conceptualised in an attraction-selection-inclusionretention framework 
In both the medical education and workforce domains, attracting a diverse applicant pool has become a priority. To this end, the four articles $^{1-4}$ in this special issue stress the importance of better understanding the backgrounds and beliefs of URM students as a basis for targeted recruitment. For instance, Southgate et al. ${ }^{1}$ emphasised strikingly different features in URM students' views about medical education and the medical profession. Similarly, Osman et al. ${ }^{2}$ revealed the differential images about doctoring held by males and females. In workforce recruitment, a parallel line of research into applicants' images of organisations as employers has shown that especially symbolic image attributes matter. ${ }^{7}$ Such symbolic attributes refer to traits (e.g. innovative, prestigious, masculine) that applicants ascribe to organisations. Importantly, people are then attracted to organisations that enable them to express something about their identity and personality. One implication is that efforts to 'brand' medical careers among URM students should focus on these symbolic trait-like attributes. In a first step, as shown by some of the studies, focus groups ${ }^{1}$ and textual analysis ${ }^{2}$ can be used to uncover the symbolic features that URM students associate with medical education and the profession. Given that these trait-like associations among URM students are often deep-rooted, in a next step it is probably more realistic to first 'unbrand' them before trying to 'rebrand' them.

Efforts to 'brand' medical careers among URM students should especially focus on these symbolic trait-like attributes

How can this branding be achieved? In workforce recruitment, there has been a shift

towards more credible and informal recruitment sources and communication. Applied to medical education, this means that recruiters and former students with backgrounds similar to those of the targeted potential candidate pool visit campuses and engage in community outreach activities to attract students. As cogently argued by Southgate et al., ${ }^{1}$ these role models provide 'hot' insider knowledge that speaks to URM students. This contrasts with referral programmes (i.e. programmes that encourage and reward employees to recruit from their existing social networks), which preserve existing disparities and are therefore not recommended. I also know of organisations that have cut their recruitment advertising budgets and instead have put substantial efforts into providing rich and valuable internships to URM students. This gives those students the 'experience' and sense of the profession they desire to have, as suggested by Southgate et al. ${ }^{1}$ When 15 - or 16year-old people enjoy the structured work experiences and internships provided to them, they become themselves ambassadors and spread the recruitment message credibly via word-ofmouth communication in their (social) networks.
In workforce recruitment, there has been a shift towards more credible and informal recruitment sources and communication

Generally, such practices (use of URM students as recruiters, internships to URM adults, and community outreach activities) are more credible than formal advertisements and expensive media campaigns because they signal to applicants that medical schools 'live their brand' and deliver their message. Critically, these practices are not only about attracting URM students, but also about targeting the mental barriers that impede their interest in and access to medical careers. I recommend that these branding efforts should also extend to the medical admission procedures used so that URM students and their significant others have positive reactions towards the tests used or at least perceive their relevance for medical education. This is because research has shown that positive test perceptions among URM candidates decrease their intentions to withdraw from the application process and increase their test motivation and test performance. ${ }^{8-10}$

When 15- or 16-year-old people enjoy structured work experiences, they become ambassadors and spread the recruitment message credibly

As noted by all four of the papers $^{1-4}$ included in the Recruitment section of this issue, medical schools face the challenge of balancing selection procedures that not only fulfil the goal of selecting people with the required standards of competence, but also admit a diverse student pool. In personnel selection, this same challenge has been called the 'validity-diversity dilemma' because of the well-documented finding that performance on the most valid tests (i.e. cognitively oriented tests) is lower for URM people (by up to 1 full standard deviation). I find it striking that over the years the domains of both medical education and personnel selection ${ }^{11,12}$ have adopted similar strategies to deal with this. One such strategy involves taking precautions (e.g. by conducting sensitivity review panels or cognitive interviewing to scrutinise item content and instructions, and 
differential item functioning to identify biased items) so that selection instruments are not developed against a majority cultural background.

Positive test perceptions among URM candidates increase their test motivation and test performance

As another communality, there is relative consensus that assessments of personal qualities and interpersonal skills should complement the traditionally used admission tests for better predicting the bedside manners of future doctors. For example, this was one of the selection strategies mentioned in the paper by Larkins et al., which makes reference to the Training for Health Equity Network. ${ }^{3}$ In a high-stakes admission process, it is additionally important that these assessments of 'soft' skills are formal and systematic. As letters of recommendations, interviews and personal statements typically do not fulfil these requirements, SJTs have emerged as a viable alternative in both domains. ${ }^{5,13,14}$ Situational judgement tests confront applicants with descriptions of standardised realistic situations and ask them to select the most appropriate response. Candidates' responses are scored on the basis of expert judgements. Meta-analyses reveal that SJTs display lower ethnic subgroup differences than cognitive ability tests, ${ }^{15}$ which leads me to conclude that SJTs kill two birds with one stone: they assess something different and they increase diversity.

There is relative consensus that assessments of personal qualities and interpersonal skills should complement traditional admission tests
A last parallel strategy across the domains of medical education and workforce recruitment deals with the provision to URM candidates of test practice and coaching with the aim of creating a more level playing field because URM students typically have less test familiarity and fewer test-taking skills. In both fields, there is a trend towards organisation-endorsed (rather than commercial) coaching, which means that the schools themselves organise the training. As evidenced by the success of the conditional acceptance programme reported by Girotti et al., ${ }^{4}$ such opportunity enhancement programmes for URM students should go beyond pure test and academic coaching and include personalised support and mentorship.

Situational judgement tests kill two birds with one stone: they assess something different and they increase diversity

In addition to these similarities, I also want to highlight three recent discoveries in personnel selection that do not appear to have been adopted in medical education. A first exciting development deals with the search for alternative cognitive ability measures, which maintain validity but do not decrease diversity efforts. Specifically, assessments of executive functioning ${ }^{16}$ which focus on $\operatorname{cog}$ nitive tasks in computer simulations that require the candidate to monitor events and to shift between tasks and so forth seem to hold a lot of promise.

As a second development, researchers have started to modify different test components (instead of changing the whole test) to isolate components that yield equally valid predictions as well as increase diversity. For instance, changing the SJT stimulus format from one that is text-based to a multimedia format ${ }^{17}$ or replacing multiplechoice items with open-ended questions (write-in items) ${ }^{18}$ seem helpful. These newer formats also enhance perceptions and test motivation among URM students. Recently, these results have been extended to three-dimensional animated and avatar-based formats ${ }^{19}$ and webcamcaptured behavioural responses. ${ }^{20}$

Assessments of executive functioning that require the candidate to monitor events and to shift between tasks seem to hold a lot of promise

Thirdly, Kuncel et al. ${ }^{21}$ conducted a recent meta-analysis in which they compared mechanical with judgement-based approaches to the integration of information gathered for selection. Mechanical integration was the winner, which suggests that the application of $a$ priori defined algorithms is preferable to minimise decision-maker idiosyncrasies and biases. More recent findings speak of which mechanical approach to use. Further details are beyond the scope of this commentary, but interested readers might examine work into Pareto-optimal weighting as an approach wherein test scores $(\operatorname{cog}$ nitive and non-cognitive) are combined into a weighted sum, thereby optimising both diversity and performance. ${ }^{22,23}$

The application of a priori defined algorithms is preferable to minimise decisionmaker idiosyncrasies and biases

In sum, these recent developments in the personnel recruitment and selection domain based in the workforce inform the extant evidence in the field of medical education. Many of these new findings can also be easily translated into practical recommendations and, as 
such, provide medical schools and researchers with a window of opportunity to experiment with strategies to further increase diversity in medical education.

\section{REFERENCES}

1 Southgate E, Kelly BJ, Symonds IM. Disadvantage and the 'capacity to aspire' to medical school. Med Educ 2015;49:73-83.

2 Osman NY, Schonhardt-Bailey C, Walling JL, Katz JT, Alexander EK. Textual analysis of internal medicine residency personal statements: themes and gender differences. Med Educ 2015;49: 93-102.

3 Larkins S, Michielsen K, Iputo J et al. Impact of selection strategies on representation of underserved populations and intention to practise: international findings. Med Educ 2015;49:60-72.

4 Girotti J, Soo Park Y, Tekian A. Ensuring a fair and equitable selection of students to serve society's health care needs. Med Educ 2015;49:84-92.

5 Lievens F. Adjusting medical school admission: assessing interpersonal skills using situational judgement tests. Med Educ 2013;47:182-9.

6 Kravitz DA. The diversity-validity dilemma: beyond selection - the role of affirmative action. Pers Psychol 2008;61:173-93.

7 Lievens F, Highhouse S. The relation of instrumental and symbolic attributes to a company's attractiveness as an employer. Pers Psychol 2003;56:75-102.

8 Chan D, Schmitt N, DeShon RP, Clause CS, Delbridge K. Reactions to cognitive ability tests: the relationships between race, test performance, face validity perceptions, and test-taking motivation. JAppl Psychol 1997;82 (2):300-10.

9 Nguyen HHD, Ryan AM. Does stereotype threat affect test performance of minorities and women? A meta-analysis of experimental evidence $J A p p l$ Psychol 2008;93 (6):1314-34.

10 Schmit MJ, Ryan AM. Applicant withdrawal: the role of test-taking attitudes and racial differences. Pers Psychol 1997;50:855-76.

11 Ployhart RE, Holtz BC. The diversity-validity dilemma: strategies for reducing racioethnic and sex subgroup differences and adverse impact in selection. Pers Psychol 2008;61:153-72.

12 Sackett PR, Schmitt N, Ellingson JE, Kabin MB. High-stakes testing in employment, credentialing, and higher education: prospects in a post-affirmative action world. $\mathrm{Am}$ Psychol 2001;56 (4):302-18.

13 Lievens F, Patterson F. The validity and incremental validity of knowledge tests, low-fidelity simulations, and high-fidelity simulations for predicting job performance in advanced-level high-stakes selection. J Appl Psychol 2011;96 (5):927-40.

14 McDaniel MA, Hartman NS, Whetzel DL, Grubb WL. Situational judgement tests, response instructions, and validity: a meta-analysis. Pers Psychol 2007;60:63-91.

15 Whetzel DL, McDaniel MA, Nguyen NT. Subgroup differences in situational judgement test performance: a meta-analysis. Hum Perform 2008;21:291-309.

16 Huffcutt AI, Goebl AP, Culbertson SS. The engine is important, but the driver is essential: the case for executive functioning. Ind Organ Psychol 2012;5:183-6.

17 Chan D, Schmitt N. Video-based versus paper-and-pencil method of assessment in situational judgement tests: subgroup differences in test performance and face validity perceptions. $J$ Appl Psychol 1997;82 (1):143-59.

18 Edwards BD, Arthur W. An examination of factors contributing to a reduction in subgroup differences on a constructedresponse paper-and-pencil test of scholastic achievement. $J A p p l$ Psychol 2007;92 (3):794-801.

19 Fetzer M, Tuzinksi K. Simulations for Personnel Selection. New York, NY: Springer 2014.

20 De Soete B, Lievens F, Oostrom J, Westerveld L. Alternative predictors for dealing with the diversityvalidity dilemma in personnel selection: the constructed response multimedia test. Int J Select Assess 2013;21:239-50.

21 Kuncel NR, Klieger DM, Connelly BS, Ones DS. Mechanical versus clinical data combination in selection and admissions decisions: a metaanalysis. J Appl Psychol 2013;98 (6):1060-72.

22 De Corte W, Sackett PR, Lievens F. Designing Pareto-optimal selection systems: formalising the decisions required for selection system development. $J A p p l$ Psychol 2011;96 (5):907-26.

23 Wee S, Newman DA, Joseph DL. More than g: selection quality and adverse impact implications of considering second-stratum cognitive abilities. J Appl Psychol 2014;99 (4):547-63. 